\title{
Establishing New Curriculum of Pathology and its Challenges at a New Medical College
}

\author{
Supriya Sandeepa ${ }^{1}$, Sandhyarani Mahadev Kanna ${ }^{1}$, Bhargavi K Nagabhushan (iD ${ }^{1,}{ }^{*}$, Archana Shetty (iD ${ }^{1}$, \\ Jessica Minal (iD ${ }^{1}$, Nikhil PV (iD) ${ }^{1}$, Aparna Muralidhar (iD) ${ }^{1}$, Nidha Gaffoor ${ }^{(i D}{ }^{1}$, Himasree Edupuganti ${ }^{1}$ and \\ Supriya Krishna ${ }^{1}$ \\ ${ }^{1}$ Department of Pathology, Dr Chandramma Dayananda Sagar Institute of Medical Education and Research, Ramanagara, Karnataka, India \\ "Corresponding author: Department of Pathology, Dr Chandramma Dayananda Sagar Institute of Medical Education and Research, Ramanagara, Karnataka, India. Email: \\ bhargavi.kn91@gmail.com
}

Received 2021 November 09; Revised 2021 December 07; Accepted 2021 December 13.

\begin{abstract}
Background: A competency-based curriculum is the key highlight of medical transformation in India, which provides an outcomebased framework requiring the integration of knowledge, skills, and values, unlike an old curriculum that did not provide a cohesive and comprehensive outlook.

Objectives: We aimed to discuss and evaluate in detail the process and setup of a new competency-based medical curriculum in the Department of Pathology and enlist the assets and challenges while doing the same.

Methods: The new curriculum was set up as per the guidelines provided by the National Medical Council, along with assistance from state university guidelines, articles from the internet and discussions with other universities all over the country.

Conclusions: As compared to the previous curriculum, the new curriculum introduces many positive changes and requires a revolutionary change in the outlook of institutions, faculty, and students. Prior preparedness, flexibility to adopt new changes, consistency and long-term commitment through the transition process from facilitators will go a long way in producing an excellent Indian medical graduate.
\end{abstract}

Keywords: Pathology, Curriculum, Competency

\section{Introduction}

A curriculum is the foundation of any educational program, and its practical implementation in medical colleges plays a vital role in producing competent doctors. There is a need to evolve from a science-based traditional medical curriculum to a competency-based curriculum that would produce an 'Indian Medical Graduate (IMG)' who can undertake the responsibilities of a primary care physician and provide holistic, preventive, promotive, curative, and palliative care with compassion, which is the ultimate goal of the new curriculum (1).

\section{Background}

Western medicine was introduced by the Portuguese and East India Company's medical officers in the 16th century (2). The formal training of Indians in medicine started by the British and was tailored from time to time to meet the local needs by various committees such as the Shrivastava committee in mid-1970 (3) and the Bajaj committee in 1986 (4). The Medical Council of India (MCI) was established in 1933 as a statutory body to form and maintain uniform standards in medical education (5). The 'Graduate Medical Regulations, 2019' amendment was made to ensure that the IMG is trained to effectively contribute to India's mission of 'Universal Health Coverage' (6). To achieve this goal, the MCI developed a competency-based contextual curriculum called "Competency-based Undergraduate Curriculum for the IMG" (7).

The old curriculum contrasts with the new curriculum, as shown in Table 1, and had to be upgraded (8) The foundation program lays the cornerstone to the new curriculum and serves to orient newly admitted students regarding the knowledge, skills, and attitudes required of them during the MBBS professional course (9). 
Sandeepa Set al.

\begin{tabular}{lcc}
\hline Table 1. Contrasting Features Between the Old and New Curriculum & & \\
\hline Variables & Old Curriculum & Competency-Based Curriculum \\
\hline Main domain & Cognitive domain & Cognitive, psychomotor, and affective domains \\
\hline Focus & Teacher-centered (10) & Student-centered \\
\hline Main method of teaching & Lectures and seminars & Interactive teaching \\
\hline Integrated teaching & Less important & Mandatory (20\% of the syllabus to be covered) \\
\hline End objective & Knowledge acquisition & Knowledge and skill acquisition \\
Outcome & Not measurable in terms of objectivity & Specific criterion-based measurable outcome \\
Attitude, ethics, and communication skills & Not incorporated & An integral part of the curriculum \\
\hline
\end{tabular}

\section{Objectives}

This article aims to discuss and evaluate in detail the process and setup of a new Competency-based Medical Curriculum in the Department of Pathology in our college. It also aims at enlisting the assets, liabilities, and challenges while doing the same.

\section{Materials}

The new curriculum was set up under the guidelines of 'Competency-based Undergraduate Curriculum for the IMG' (9), articles from the internet on the implementation of new curricula in India (6-14), through discussions with MBBS phase I departments in our institution (Anatomy, Physiology, and Biochemistry), state university guidelines (15), and inputs from institutions of other universities in the country.

\section{Methodology}

This overnight metamorphosis of curriculum posed a herculean task to the medical faculty (11). After a thorough reading and discussion of the reference documents, we made a checklist for developing a curriculum program for our subject (Table 2 ).

\subsection{Updating our Knowledge and Sensitization About New Cur- riculum}

The second phase of the MBBS course is 12 months in duration and is divided into three blocks of four months each. To begin with, the faculty had to understand the definition of terms like core, non-core, competencies, domain, level, etc., which were studied through formal and informal training. The official training was called Revised Basic Medical Education Training or Curriculum-based Medical Education training- basic and advanced levels under the Curriculum Implementation Support Program (CISP) organized by the Regional Medical Education Unit as advised by MCI (now the National Medical Council, NMC). The training aims at transforming teachers into learning facilitators with a whole new perspective and more responsibility towards students' knowledge and skill acquisition (12). During the initial phase, the entire faculty underwent basic level training and started setting up a new curriculum.

Being a novel institute with an ongoing admission process for the first year, we made our goals clear about what a student should achieve at the end of the course. The main aim was to provide a solid foundation to understand the pathophysiology of diseases, which would help the IMG correlate and diagnose the patient's ailment and acquire the essential practical skills to understand laboratory reports for planning the management of the patient.

The standard reference for setting up the curriculum was a document issued by MCI, titled "Competency-based Undergraduate Curriculum for the IMG (Hereon referred to as CBME document)" (9). In this document [refer to Figure 1(9)], the competencies for the subjects are already prepared by the MCI, and it also provides possible areas of integration, suggested TLM, type of assessment, and skill certification requirements (9).

\subsection{Listing of Competencies and Deriving SLOS}

The subject of pathology has 181 competencies, which the MCI has already designated. Over the past four years, a group of highly committed medical professionals working as its members has derived these critical competencies now available in the CBME document. Competency is an observable ability of health professionals that integrates knowledge, skills, ability, and values (13), e.g., for performing a laboratory test or diagnosing meningitis. Pertinent SLOs were derived from each competency such that all aspects of competency were covered concerning that topic. The same was enlisted in a spreadsheet (Table 3 ). 


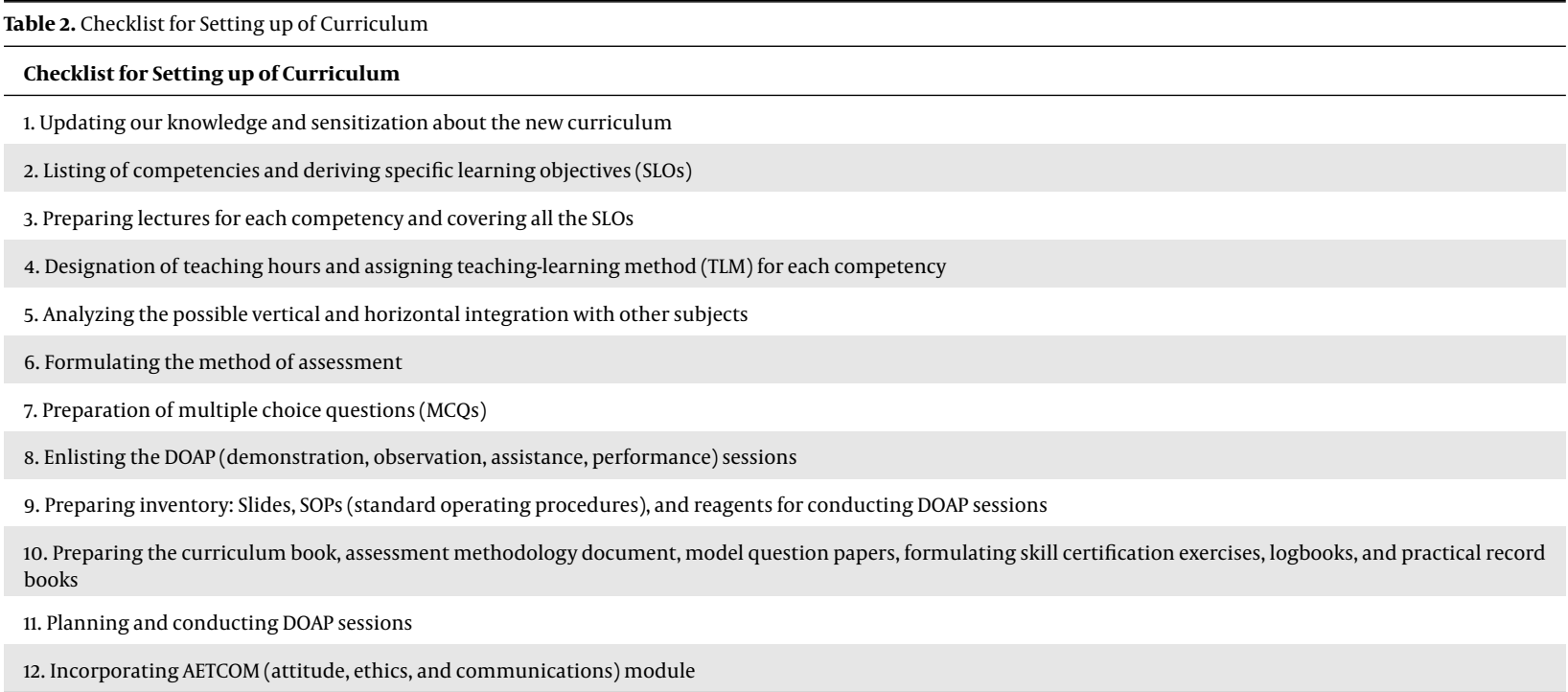

\section{Understanding the competencies table}

\begin{tabular}{|c|c|c|c|c|c|c|c|c|c|c|}
\hline A & B & C & D & E & F & G & H & I & J \\
\hline No. & Competencies & Domain & K/KH/SH/P & Core & $\begin{array}{c}\text { Suggested } \\
\text { Teaching } \\
\text { Learning Method }\end{array}$ & $\begin{array}{c}\text { Suggested } \\
\text { Assessment } \\
\text { method }\end{array}$ & $\begin{array}{c}\text { No. } \\
\text { required to } \\
\text { certify (P) }\end{array}$ & $\begin{array}{c}\text { Vertical } \\
\text { Integration }\end{array}$ & $\begin{array}{c}\text { Horizontal } \\
\text { Integration }\end{array}$ \\
\hline Physiology & & & & & & & & \\
\hline S
\end{tabular}

Summary

Number of Competencies: (08)

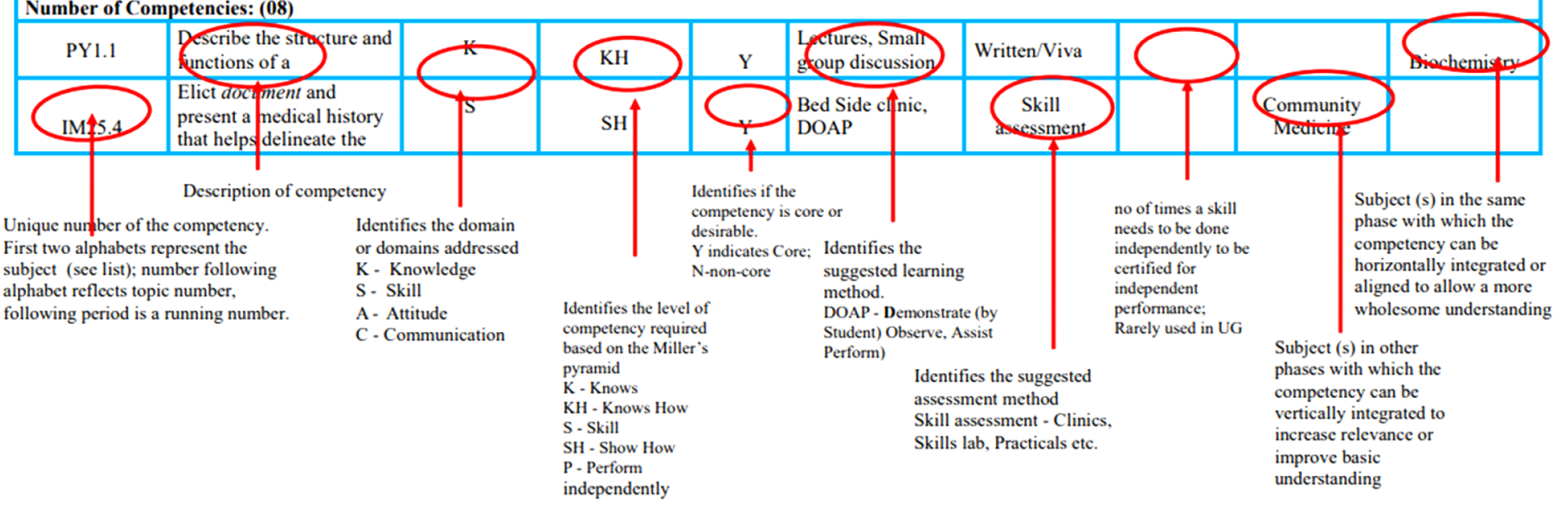

Figure 1. Understanding the competency table

\begin{tabular}{|c|c|c|c|c|c|c|c|c|c|}
\hline Competency No. & Topic & Competency & $\begin{array}{l}\text { Teaching } \\
\text { Learning } \\
\text { Method }\end{array}$ & Time Duration & SLO-1 & SLO-2 & SLO-3 & SLO-4 & SLO-5 \\
\hline PA15.1 & $\begin{array}{l}\text { Macrocytic } \\
\text { anemia }\end{array}$ & $\begin{array}{l}\text { Describe the } \\
\text { metabolism of } \\
\text { Vitamin B12 and } \\
\text { the etiology and } \\
\text { pathogenesis of } \\
\text { B12 deficiency }\end{array}$ & $\begin{array}{l}\text { Charts and } \\
\text { problem-based } \\
\text { learning }\end{array}$ & 1 hour & $\begin{array}{l}\text { Describe the } \\
\text { normal } \\
\text { metabolism of } \\
\text { Vitamin B12 and } \\
\text { folic acid. }\end{array}$ & $\begin{array}{l}\text { Describe the } \\
\text { functions of } \\
\text { Vitamin B12 and } \\
\text { folic acid. List the } \\
\text { food sources rich } \\
\text { in Vitamin B12 } \\
\text { and folic acid. }\end{array}$ & $\begin{array}{l}\text { Describe the } \\
\text { Etiopathogenesis } \\
\text { of megaloblastic } \\
\text { anemia }\end{array}$ & $\begin{array}{l}\text { Describe the } \\
\text { clinical features } \\
\text { and } \\
\text { complications of } \\
\text { Megaloblastic } \\
\text { anemia. }\end{array}$ & $\begin{array}{l}\text { Describe the } \\
\text { pathogenesis of } \\
\text { pernicious } \\
\text { anemia. }\end{array}$ \\
\hline
\end{tabular}




\begin{tabular}{l|l}
\multicolumn{1}{c|}{$\begin{array}{c}\text { Large group } \\
\text { teaching(LGT) }\end{array}$} & \multicolumn{1}{c}{$\begin{array}{c}\text { Small group } \\
\text { teaching(SGD) }\end{array}$} \\
\hline - Didactic lectures & - Symposium \\
- *Team Based learning & - Seminars \\
- *Seminars & - Problem based learning \\
- *Tournament & - Case-based approach \\
- *Pick and Speak & - Quiz \\
& - Self-directed learning \\
& etc \\
\hline
\end{tabular}

Figure 2. Adopted methods of teaching

\subsection{Preparing Lectures for Each Competency Covering All SLOs}

The SLOs were taken as smaller targets to achieve the final goal of the particular competency. The teaching faculty prepared lectures/teaching material in Microsoft Word document with reference to SLOs from standard textbooksRobbins and Cotran Pathologic Basis of disease, the Textbook of Pathology by Dr. Harsh Mohan and other standard references in a stepwise manner.

Each competency taken as a single lecture $\rightarrow$ Competencies distributed among all faculties $\rightarrow$ A skeleton framework with whole learning material prepared $\rightarrow$ Lectures crosschecked $\rightarrow$ Hyperlinking of lectures to competency table.

The next task was the designation of TLMs and teaching hours to the above competencies.

\subsection{Designation of Teaching Hours and Assigning TLM to Each Competency}

The competencies were allotted appropriate teaching hours following the master timetable provided to our subject. According to the new curriculum, only $30 \%$ of the portion should be covered as didactic lectures, and the rest should be more interactive TLMs. The learning process should include clinical experiences, a problem-oriented approach, case studies, and community health care activities (9). The faculty met twice a week to discuss the TLMs and finalize the apt and feasible methods to be inculcated in the new curriculum. Our search for interactive teaching methods yielded 300 ways (14) to make lectures interesting and different methods of small group teaching. For large group teaching (LGT) and small group discussion (SGD), the following methods were decided upon [refer to Figure $2(14)$.

*For methods 2 to 5 in LGT, the topic will be intimated to students in advance, and teaching material is provided to form a basis for discussion during the execution of the learning method.
Considering the infrastructure, faculty numbers, student numbers, teaching resources, feasibility, and time management, various TLMs must be pre-decided to be ready with appropriate learning material and other practical arrangements (e.g., for the availability of adequate staff, availability of classrooms) (8).

\subsection{Analyzing Possible Vertical and Horizontal Integration [ for Definition Refer to CBME Document (9)]}

The new curriculum has the added advantage of integration, which aims to provide a comprehensive outlook about the topic under discussion, leads to an enhanced understanding of the subject, and allows better problemsolving. It is recommended that integration be limited to $20 \%$ of the total curriculum (7). The possible areas of integration have been suggested in the CBME document but can be customized by the institution according to their preference. We decided to integrate topics such as anemia, rheumatic heart disease, diabetes mellitus, and tuberculosis that are clinically important and common in the Indian scenario (refer to Table 4).

\subsection{Formulating the Method of Assessment}

The competency table requires formulating the assessment methods beforehand, which had to be focused on knowledge application, skill acquisition and has to be specific criterion-based. Three types of assessment (Figure 3) were decided upon: formative assessment, summative assessment, and internal assessment (9). The assessment methods had to be planned (as shown in Table 5) and kept ready to maintain uniformity (9).

The OSPE/OSCE-objective structured practical/clinical examination is the core of practical knowledge assessment (16). The marks distribution for practical exercises (now formulated in the form of OSPE/OSCE in which marks are given for each step followed for that specific exercise), spotters, record books, logbooks, and viva was formulated and documented in the assessment methodology document. The objective of assessments would be to assess proficiency and skills to conduct experiments and clinical examination, interpret data, and form a logical conclusion, wherever applicable. Our main concern was formative assessments, which were to be taken during learning sessions. For this purpose, we decided to use MCQs, tutorials, projects, papers, and poster competitions as a form of theoretical assessment. With this in view, we first discussed the type and method of formulating MCQs. 
Sandeepa Set al.

\begin{tabular}{|c|c|c|c|c|c|c|}
\hline Variable & Pathology & Microbiology & Pharmacology & Forensic medicine & $\begin{array}{l}\text { Community } \\
\text { medicine }\end{array}$ & $\begin{array}{l}\text { Concerned clinical } \\
\text { subjects }\end{array}$ \\
\hline Block 1 & $\begin{array}{l}\text { Immunology; } \\
\text { Anemia; Wound } \\
\text { healing; Shock }\end{array}$ & $\begin{array}{l}\text { Immunology; Shock; } \\
\text { Surgical practice; } \\
\text { Infective endocarditis } \\
\text { and rheumatic heart } \\
\text { disease }\end{array}$ & $\begin{array}{l}\text { Immunology; } \\
\text { Anemia; Essential } \\
\text { medicines; } \\
\text { Toxicology }\end{array}$ & $\begin{array}{l}\text { Wound healing; } \\
\text { Toxicology }\end{array}$ & Essential medicines & $\begin{array}{l}\text { Shock; Surgical } \\
\text { practice; Infective } \\
\text { endocarditis and } \\
\text { rheumatic heart } \\
\text { disease; } \\
\text { Immunization }\end{array}$ \\
\hline
\end{tabular}

\section{Formative Assessment - An assessment conducted during the lectures/competencies to} provide feedback to improve leaming

Summative Assessment-An assessment conductedat the end of a topic to examine how much the student has leamt.

Intemal Assessment-An assessment to know what is leamt at the end of each block of subject and serves both formative and summative functions.

Figure 3. Types of assessment

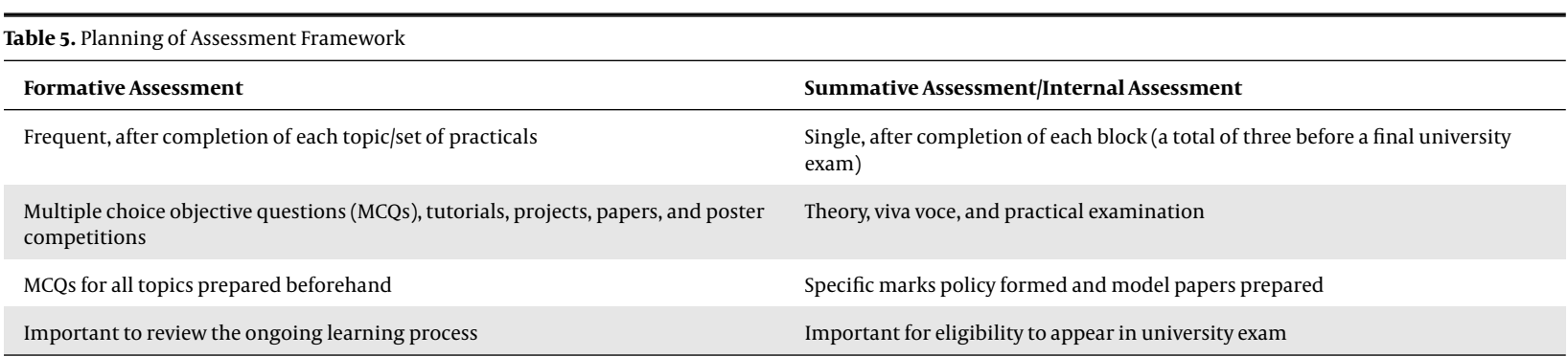

\subsection{Preparation of MCQs}

The MCQs are important from the perspective of competitive exams, and we used this to our advantage by utilizing them as essential assessment tools. We chose to use the different types of MCQs: (1) single best response; (2) match the following; (3) extended MCQs; (4) assertion and reason type; (5) true or false; and (6) image-based (gross pictures, microscopic images, graphs, and electron microscopic pictures). Competencies were divided among all the faculties, and the MCQs were prepared beforehand with answer keys and references. They were counter-checked by other faculties and ensured for correctness. Other forms of assessment did not require prior preparation. The MCQs were also part of the internal assessment, and specific marks 
were allotted for them in question papers. The assessment framework was ready, but the main challenge we faced was planning the DOAP sessions.

\subsection{Enlisting the DOAP Sessions}

The practical sessions in pathology are now termed DOAP sessions (9). These were separately enlisted and divided into hematology, clinical pathology, cytology, and histopathology. Possible integrated DOAP sessions were coordinated with the concerned departments, ensuring that the pathology part for that session was covered.

\subsection{Preparing the Inventory (Slides, SOPs, Reagents) for Con-} ducting DOAP Sessions

The reagents (functionality checked with positive samples), specimens, slides and instruments required for the above exercises were enlisted, indented/prepared, labelled and arranged. Demo exercise and trained technician was kept ready for practical sessions. Hematology slides for practicals of anemia and leukemias were collected from hematology section of hospital laboratory. Adequate duplicate slides were prepared and stained with Leishman stain, then mounted and filed in slide boxes. Similar exercises were done for histopathology and cytology.

Histopathology slides were prepared from tissue sections obtained during our routine grossing and from archived specimens and blocks. They were stained with natural hematoxylin, which was prepared and ripened over three months beforehand. It was ensured that only one section with classical features was taken. Some of the rare cases, such as leprosy, rhinosporidiosis, etc., were acquired through a request from other private laboratories or medical colleges.

Cytology slides were difficult to prepare due to technical aspects (100 fibroadenoma cytology slides cannot be collected from a patient, and representative slides cannot be assured). A representative and classical case was collected, which would be displayed to the entire class.

The pathology museum was designed to further the literary resources for the students. We were fortunate to obtain a wide range of classical histopathology specimens and blocks for DOAP sessions and the museum from renowned laboratories and hospitals in and around Bengaluru. An extensive collection of specimens was displayed with relevant clinical, gross, and microscopic details present in the hand-outs and in the form of the museum catalog.

An E-kiosk at the museum helped index and guide students. A video library was also set up, with short videos demonstrating procedures such as frozen sections, grossing of radical specimens, etc. The DOAP sessions are the backbone of the basic skill acquisition process. The documentation of the performance of the exercises had to be done in the practical record book and logbook.

\subsection{Preparing the Log Book and Practical Record Book}

A practical record book had to be prepared and printed before the students arrived. The DOAP sessions were compiled, indexed, and divided according to subsections. For the specimens and slides, space was incorporated for the diagrams and description. A separate section was devoted to gross specimens, instruments, and charts.

The NMC requires specific skills to be certified to label an IMG to be proficient in practical knowledge of pathology. Hence, in the end, the certification skills were incorporated into the practical record. Three such skills are mandatory according to NMC competency: (1) PA16.6, (2) PA25.6, and (3) PA35.3 (9) (letters 'PA' designated to pathology). The next step was to prepare the student logbook.

The logbook had a record of all the student's activities throughout the second phase. Competencies-such as DOAPs/skill certification, students' behavior assessment, scores in all exams, seminars presented by them, sessions of self-directed learning, and extracurricular activities, were included in the logbook. The basic format of the logbook is given in the module provided by NMC. Conducting the DOAP sessions within a particular timeframe is essential to ensure that all the topics are covered and adequate time for revision and skill certification process is available.

\subsection{Planning DOAP Sessions and Master Time Table}

Before the academic year, the master timetable had to be submitted to the zonal center. According to the months available, the second professional MBBS was divided into three blocks. All the second, third, and fourth-year subject faculties coordinated and framed the timetable.

The competencies to be covered, including theory and SGD sessions for the second MBBS, were prepared. During the weekdays, time was allotted for conducting DOAP sessions, self-directed learning, and AETCOM. With a batch of 150 students (divided into two batches), a blue print for conducting practical sessions was finalized. The next step was incorporating the AETCOM module into the teaching process, which was a novel exercise for all the disciplines across the course of MBBS. 


\subsection{Incorporating the AETCOM Module}

The new curriculum aims to develop an IMG as a compassionate doctor. With this intent, the attitude, ethics, and communication module was incorporated into the curriculum. Besides, 75\% attendance in the Professional Development Program (AETCOM module) is required for eligibility to appear for final examination in each professional year [vide Medical Council of India Notification on Graduate Medical Education (Amendment) Regulations 2019, published in the Gazette of India Part III, Section 4, issued on 4th November 2019] (9). The AETCOM module will be a longitudinal program. One competency under the AETCOM module was allotted to the Department of Pathology, for which respective SLOs were prepared and incorporated in the timetable. The TLMs employed were group discussions and role-plays.

In the end, we would ensure that we are on the right track by taking frequent feedback from students through feedback forms and face-to-face discussions, which will provide a quality check through our process of the new curriculum implementation program.

With the above steps and preparation, we are ready to welcome the initial second year batch of our college and await if our preparedness is successful in achieving the goal of making a good IMG.

\section{Discussion}

We had a lot of advantages and disadvantages while setting up the new curriculum (refer to Figure 4). According to a small survey conducted via google forms, telephonic conversations, and faculty discussions, we found that different colleges had different perspectives and approaches towards setting up new curricula. The staff in different colleges were unsure whether the new curriculum would bring the positive change it intends to. The competencies and SLOs were collaboratively formed by colleges under a single university and were not customized according to their institutes. Thus, it was more universitycentered than college-centered. The TLMs were not extensively discussed and researched upon, which is critical in shifting curricula from lecture-based to interactive teaching. The process of framing the assessment methods, planning of DOAP sessions, preparing curriculum documents, and other related documents was similar to other institutes.
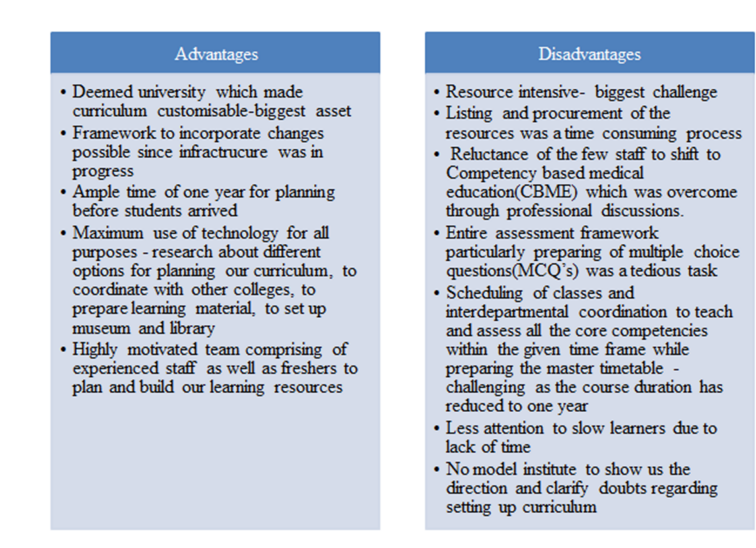

Figure 4. Advantages and disadvantages while setting up the new curriculum

\section{Conclusion}

As compared to the previous curriculum, the new version introduces many changes and requires a revolutionary change in the outlook of institutions, faculty, and students. Although it is well-drafted and defined with competencies as its base and skill acquisition as its key element, it requires massive effort to set up and put into practice. Prior preparedness, flexibility to adapt and acquire new changes, consistency, and a long-term commitment through the transition process from facilitators will go a long way in producing an excellent IMG.

\section{Acknowledgments}

We would like to express our gratitude to our former Head of department, late Dr.(Col) Nikhil Moorchung sir, who developed the idea of this study. The innovative ideas stemmed from his love for teaching, which has aided in successful implementation of the new curriculum.

\section{Footnotes}

Authors' Contribution: S.S., K.S.M., and B.K.N., developed the protocol and wrote the manuscript; A.S., J.M., and N.P.V. helped to draft the manuscript; A.M., N.G., H.E., and S.K., critically revised the manuscript for important intellectual content. Dr.(Col) Nikhil Moorchung-developed the idea of this study.

Conflict of Interests: There is no conflict of interest.

Funding/Support: There is no funding/support. 


\section{References}

1. Sharma R, Bakshi H, Kumar P. Competency-Based Undergraduate Curriculum: A Critical View. Indian J Community Med. 2019;44(2):77-80. doi:10.4103/ijcm.IJCM_206_19.[PubMed:31333280].[PubMed Central: PMC6625257].

2. Mushtaq MU. Public health in british India: A brief account of the history of medical services and disease prevention in colonial India. Indian J Community Med. 2009;34(1):6-14. doi: 10.4103/0970-0218.45369. [PubMed: 19876448]. [PubMed Central: PMC2763662].

3. Shrivastav JB. Health Services and Medical Education: A Programme for Immediate Action. New Delhi, India: Ministry of Health and Family Planning, Government of India; 1975.

4. Bajaj JS. Bajaj Committee Report. New Delhi, India: Ministry of Health \& Family Welfare, Government of India; 1986.

5. Goswami S, Sahai M. Problems and Challenges in Medical Education in India. EurJ Contemp Educ. 2015;11(1):31-7. doi: 10.13187/ejced.2015.11.31.

6. Misra S, Fichadiya N, Kariya V. Implementation of Foundation Program under "Graduate Medical Regulations 2019" for first professional MBBS students at a Medical College located in western India - A transformative learning experience. MedEdPublish. 2020;9:64. doi: 10.15694/mep.2020.000064.1.

7. Ananthakrishnan N. Competency based undergraduate curriculum for the Indian Medical Graduate, the new MCI curricular document: Positives and areas of concern. SBV J Basic Clin Appl Heatlh Sci. 2018;1(1):34-42. doi: 10.5005/jp-journals-10082-01149.

8. Shrivastava S, Shrivastava P. Competency-based medical education for undergraduates in India: Strengths, weaknesses, opportunities, challenges analysis and the way forward. Mustansiriya Medical Journal. 2020;19(1):37. doi: 10.4103/mj.mj_1_20.

9. Medical Council of India. Competency based under graduate curriculum for the Indian Medical Graduate. New Delhi, India: National Medical Commission; 2020, [cited 23rd Jun 2021]. Available from: https: //www.nmc.org.in/information-desk/for-colleges/ug-curriculum/.

10. Shrivastava S, Shrivastava P. How to successfully implement competency-based medical education in India. Education in the Health Professions. 2018;1(2):61. doi: 10.4103/ehp.ehp_20_18.

11. Kumar V, Rajasekhar SS. Overarching challenges to be addressed before implementing competency-based medical education in India. BLDE Univ J Health Sci. 2019;4(1):44. doi: 10.4103/bjhs.bjhs_5_19.

12. Chacko T. Moving toward competency-based education: Challenges and the way forward. Arch Med Health Sci. 2014;2(2):247. doi: 10.4103/2321-4848.144365.

13. Bansal P, Supe A, Sahoo S, Vyas R. Faculty development for competency based medical education: Global, national and regional perspectives. Natl J Integr Res Med. 2017;8(5).

14. Yee K. Interactive Techniques. Florida, USA: University of Central Florida; 2020. Available from: https://www.usf.edu/atle/documents/ handout-interactive-techniques.pdf.

15. Rajiv Gandhi University of Health Sciences. Revised Ordinance Governing MBBS DEGREE COURSE AND CURRICULUM of Phase II Subjects-RS4. Karnataka, India: Rajiv Gandhi University of Health Sciences; 2020.

16. Velou MS, Ahila E. Expectations and challenges of early clinical exposure programme for first year medical students in India. IAIM. 2020;7(8):59-65. 